Supporting Information

\title{
Pr-doped $\mathrm{LaCoO}_{3}$ Towards Stable and Efficient Oxygen Evolution
}

\section{Reaction}

Renjie Xie ${ }^{\dagger}$, Zhiwei Nie ${ }^{\dagger}$ Xiangchen $\mathrm{Hu}^{\dagger}$, Yi $\mathrm{Yu}^{\dagger}$, Carmela Aruta ${ }^{\dagger}$ and Nan Yang ${ }^{\dagger *}$ $\uparrow$ School of Physical Science and Technology, ShanghaiTech University, Shanghai, 201210, P. R. China.

E-mail: yangnan@shanghaitech.edu.cn

†CNR-SPIN, UOS Roma, Area della Ricerca di Tor Vergata, I-00133 Rome, Italy

The word file concludes:

Figure S1 Schematic illustration of LPC-50/Ni foam working electrode.

Table S1 Lattice parameter of $\mathrm{La}_{1-x} \mathrm{Pr}_{\mathrm{x}} \mathrm{CoO}_{3}$

Figure S2 SEM images of (a) LPC-25 (b) LPC-75

Figure S3 BET $\mathrm{N}_{2}$ adsorption isotherms and the corresponding surface areas of LCO, LPC-50, and PCO powders

Figure S4 (a) HRTEM image of LCO (b) The magnified image of the region within red rectangle in (a), (c) HAADF-STEM image of LCO, and the corresponding EDS maps (d-f).

Figure S5 (a) HRTEM image of PCO (b) The magnified image of the region within red rectangle in (a), (c) HAADF-STEM image of PCO, and the corresponding EDS maps (d-f).

Table S2 The performance of representative OER catalysts reported in the literature.

Figure S6 Cyclic voltammograms of (a) LCO, (b) LPC-25, (c) LPC-50, (d) LPC-75 and (e) PCO measured in the double layer capacitance region 0.92-1.02 V vs. RHE at the scan rates of $5,10,20,40,80$ and $160 \mathrm{mV} \cdot \mathrm{s}^{-1}$ in $1.0 \mathrm{M} \mathrm{KOH}$ solution.

Figure S7 Plots of average double layer capacitive currents as a function of the scan rate for catalysts. The double-layer capacitance values were obtained by performing the linear fitting.

Figure S8 The specific activity of LCO, LPC-50 and PCO normalized respect to the surface areas obtained from the ECSA and BET at $500 \mathrm{mV}$ overpotential

Figure S9 Chronopotentiometric measurements of LCO, LPC-50, PCO, $\mathrm{IrO}_{2}$, $\mathrm{Pr}_{0.5} \mathrm{Ba}_{0.5} \mathrm{CoO}_{3}$ and $\mathrm{La}_{0.6} \mathrm{Sr}_{0.4} \mathrm{CoO}_{3}$ supported on $\mathrm{Ni}$ foam at $10 \mathrm{~mA} \cdot \mathrm{cm}^{-2}$.

Figure S10 The XPS spectra of (a) O 1s and (b) Co 2p of as-prepared and post-OER LPC-50 catalyst

Figure S11 (a) La $3 d$, (b) Pr $3 d$ and O $1 s$ core level XPS spectra of LCO, LPC-25, LPC50, LPC-75, and PCO powders.

Table S3 Binding energy (BE), FWHM and area percent of the La $3 d_{5 / 2}$ fitting components of LCO, LPC-25, LPC-50, LPC-75, and PCO.

Table S4 Binding energy (BE), FWHM and area percent of $\operatorname{Pr} 3 d$ fitting components 
of LPC-25, LPC-50, LPC-75 and PCO.

Figure S12 (a) Co $2 p$ XPS spectra of LCO, LPC-25, LPC-50, LPC-75 and PCO. (b) Concentration of satellite peak $\mathrm{C}$ with respect to $\mathrm{Co} 2 \mathrm{p}_{3 / 2}$ total area which corresponds to $\mathrm{Co}^{3+}$ charge transfer as described in the text. (c) Relative concentration of $\mathrm{Co}^{2+}$ valence state calculated from the $\mathrm{C}$ and $\mathrm{D}$ satellite peak area.

Figure S13 Chemical composition of $\mathrm{Pr}$ and $\mathrm{O}$. The stoichiometry expressed in terms of $\mathrm{Pr} /(\mathrm{La}+\mathrm{Pr}+\mathrm{Co}+\mathrm{O})$ in (a) and $\mathrm{O} /(\mathrm{La}+\mathrm{Pr}+\mathrm{Co}+\mathrm{O})$ in (b) area ratio. The doted red lines are the nominal values.

Figure S14 Valence band spectra and component analysis. (a) Valence band (VB) spectra of LCO, LPC-25, LPC-50, LPC-75 and PCO together with the fit as described in the text. (b) Behavior of $\operatorname{Pr}$ component area\% with different $\operatorname{Pr}$ doping concentration $\mathrm{x}$, obtained from the fit of panel (a).

Table S7 Binding energy (BE), FWHM and area percent of the VB fitting components of LCO, LPC-25, LPC-50, LPC-75 and PCO.

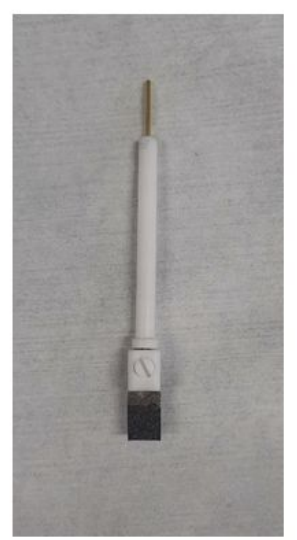

Figure S1 Schematic illustration of LPC-50/Ni foam working electrode.

Table S1 Lattice parameter of $\mathrm{La}_{1-\mathrm{x}} \mathrm{Pr}_{\mathrm{x}} \mathrm{CoO}_{3}$

\begin{tabular}{cccc}
\hline As-prepared catalysts & Crystal orientation & Two theta $\left({ }^{\circ}\right)$ & Lattice constant $(\boldsymbol{\AA})$ \\
\hline LCO & $(110)$ & 32.90 & 3.85 \\
LPC-25 & $(110)$ & 32.99 & 3.84 \\
LPC-50 & $(220)$ & 33.26 & 3.81 \\
LPC-75 & $(220)$ & 33.35 & 3.80 \\
PCO & $(220)$ & 33.40 & 3.79 \\
\hline
\end{tabular}

We assume that as-prepared catalysts $\mathrm{La}_{1-\mathrm{x}} \mathrm{Pr}_{\mathrm{x}} \mathrm{CoO}_{3}$ are in the pseudocubic structure for simplication. As shown in Table S1, the lattice constant decreases with increasing $\mathrm{Pr}$ doping concentration. 
(a)

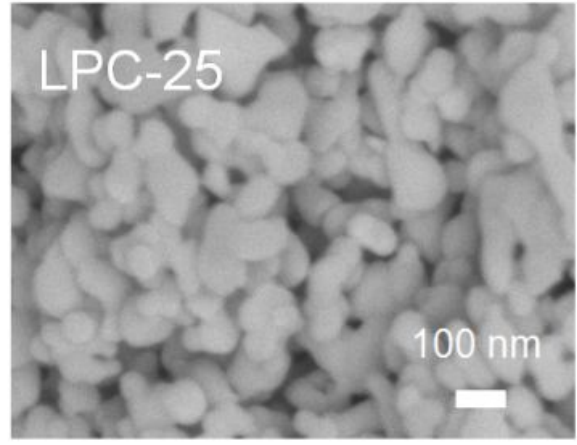

(b)

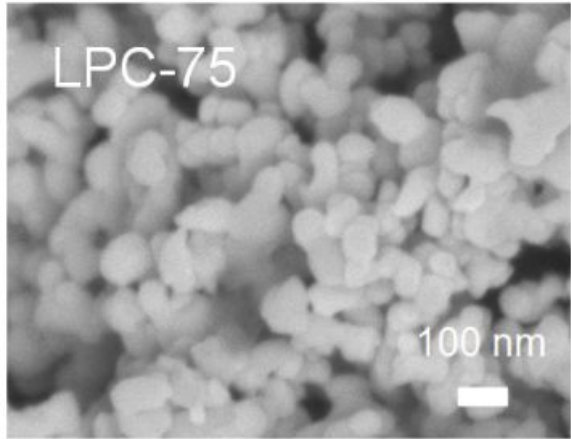

Figure S2 SEM images of (a) LPC-25 (b) LPC-75

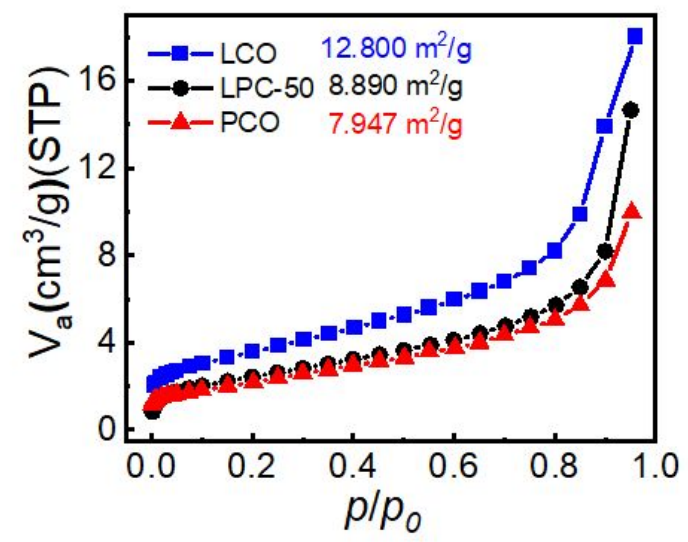

Figure S3 BET $\mathrm{N}_{2}$ adsorption isotherms and the corresponding surface areas of LCO, LPC-50, and PCO powders 

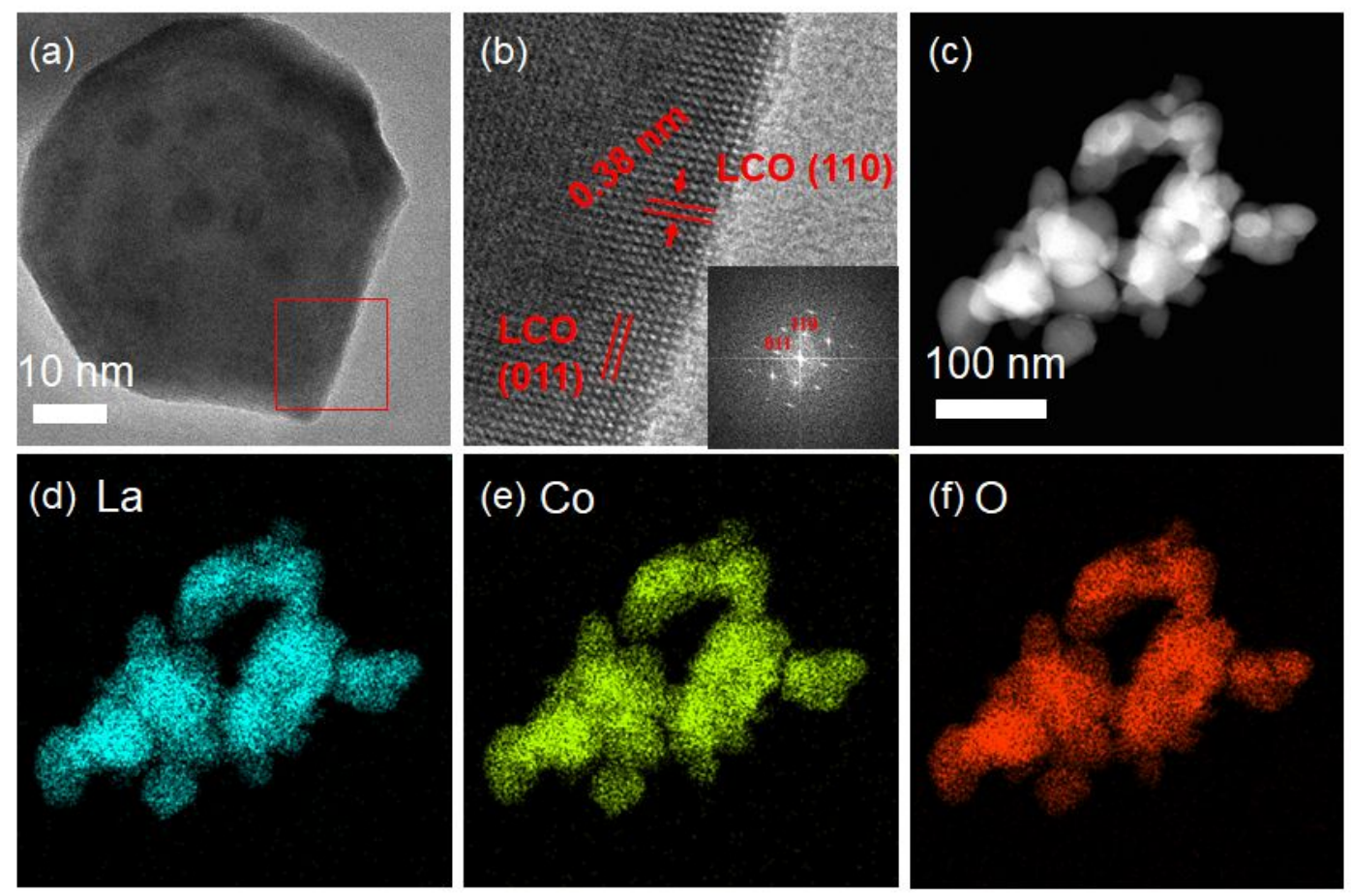

Figure S4 (a) HRTEM image of LCO (b) The magnified image of the region within red rectangle in (a), (c) HAADF-STEM image of LCO, and the corresponding EDS maps (d-f).
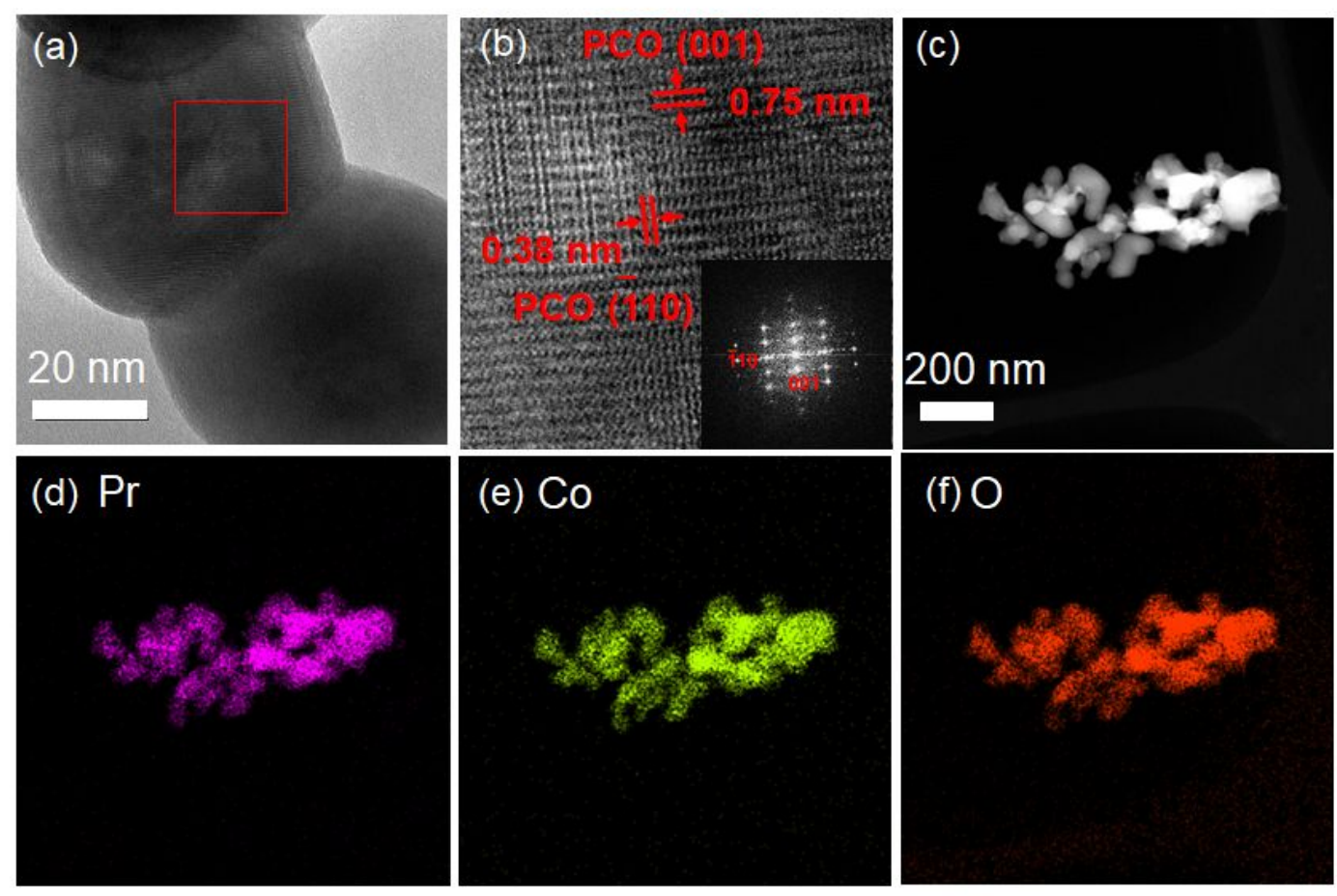

Figure S5 (a) HRTEM image of PCO (b) The magnified image of the region within red rectangle in (a), (c) HAADF-STEM image of PCO, and the corresponding EDS maps (d-f). 
Table S2 The performance of representative OER catalysts reported in the literature

\begin{tabular}{|c|c|c|c|c|}
\hline Catalyst & $\begin{array}{c}\text { Overpotential } \\
\qquad(\mathrm{mV})\end{array}$ & $\begin{array}{c}\text { Tafel } \\
\text { slope }(\mathrm{mV} / \mathrm{dec})\end{array}$ & Electrolyte & Reference \\
\hline 3D microporous- $\mathrm{LaFeO}_{3}$ & 470 & 62 & $1 \mathrm{M} \mathrm{KOH}$ & 1 \\
\hline $3 \mathrm{D}$ microporous-LaFe $\mathrm{L}_{0.8} \mathrm{Co}_{0.2} \mathrm{O}_{3}$ & 410 & 56 & $1 \mathrm{M} \mathrm{KOH}$ & 1 \\
\hline $\mathrm{La}_{0.7} \mathrm{Sr}_{0.3} \mathrm{Co}_{0.7} \mathrm{Fe}_{0.3} \mathrm{O}_{3}-975$ & 440 & 103 & $1 \mathrm{M} \mathrm{KOH}$ & 2 \\
\hline $\mathrm{La}_{0.7} \mathrm{Sr}_{0.3} \mathrm{Co}_{0.25} \mathrm{Mn}_{0.75} \mathrm{O}_{3-\delta} \mathrm{NPs}-800$ & 340 & 111 & $1 \mathrm{M} \mathrm{KOH}$ & 3 \\
\hline $\mathrm{SrCo}_{0.4} \mathrm{Fe}_{0.2} \mathrm{~W}_{0.4} \mathrm{O}_{3-\delta}$ & 399 & 58 & $1 \mathrm{M} \mathrm{KOH}$ & 4 \\
\hline $\mathrm{SrCo}_{0.4} \mathrm{Fe}_{0.2} \mathrm{~W}_{0.05} \mathrm{O}_{3-\delta}$ & 476 & 102 & $1 \mathrm{M} \mathrm{KOH}$ & 4 \\
\hline Ball-milled $\mathrm{SrCo}_{0.4} \mathrm{Fe}_{0.2} \mathrm{~W}_{0.4} \mathrm{O}_{3-\delta}$ & 357 & 81 & $1 \mathrm{M} \mathrm{KOH}$ & 4 \\
\hline $\mathbf{L a}_{0.5} \mathrm{Sr}_{0.5} \mathbf{N i}_{0.4} \mathrm{Fe}_{0.6} \mathrm{O}_{3-\delta}$ & 365 & 85 & $1 \mathrm{M} \mathrm{KOH}$ & 5 \\
\hline FeCo@NG/NCNT & 311 & 77 & $1 \mathrm{M} \mathrm{KOH}$ & 6 \\
\hline $\mathrm{Co}_{3} \mathrm{O}_{4}-\mathrm{MTA}$ & 401 & 84 & $1 \mathrm{M} \mathrm{KOH}$ & 7 \\
\hline $\mathrm{La}_{0.7} \mathrm{Sr}_{0.3} \mathrm{CoO}_{3-\delta}$ & 326 & 71 & $1 \mathrm{M} \mathrm{KOH}$ & 8 \\
\hline $\mathrm{La}_{0.6} \mathrm{Ca}_{0.4} \mathrm{CoO}_{3} / \mathrm{Sb}: \mathrm{SnO}_{2}$ & 470 & -- & $1 \mathrm{M} \mathrm{KOH}$ & 9 \\
\hline LPC-50 & 312 & 81 & $1 \mathrm{M} \mathrm{KOH}$ & This work \\
\hline
\end{tabular}
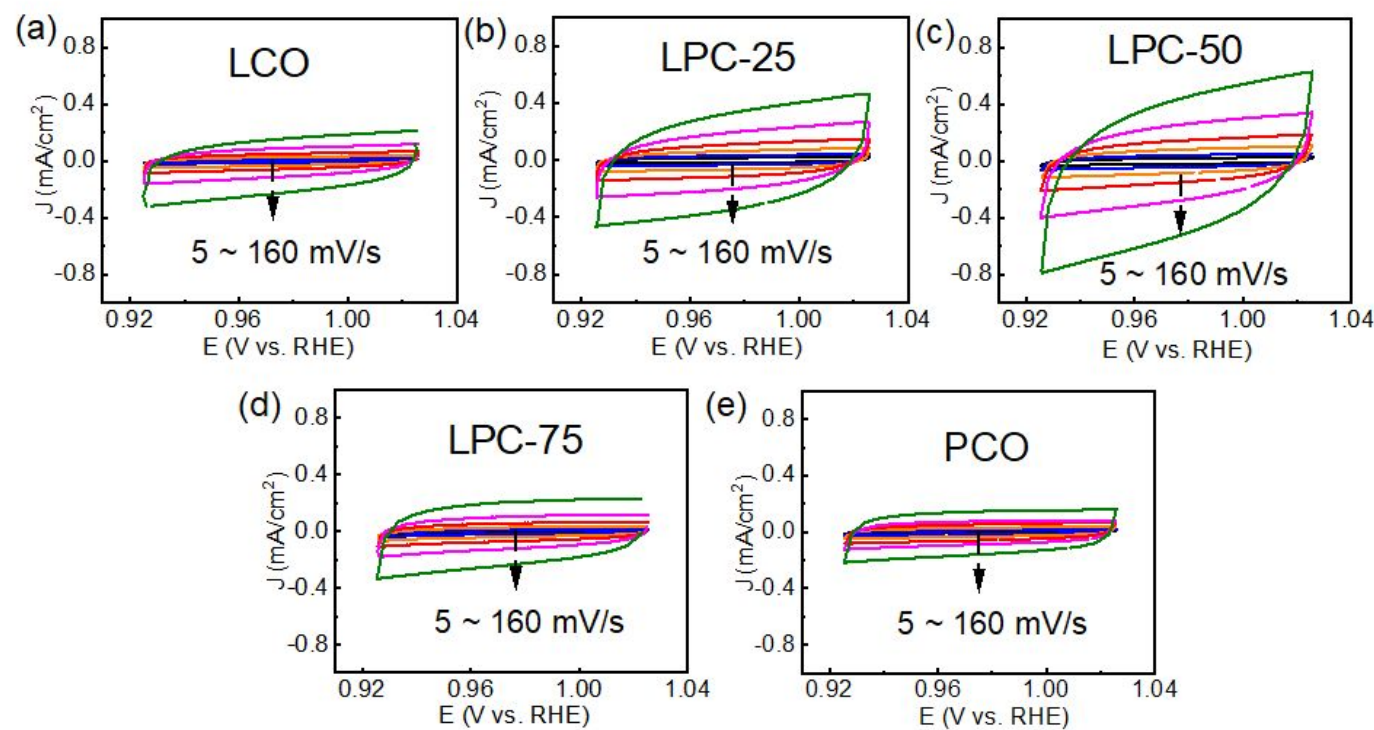

Figure S6 Cyclic voltammograms of (a) LCO, (b) LPC-25, (c) LPC-50, (d) LPC-75 and (e) PCO measured in the double layer capacitance region $0.92-1.02 \mathrm{~V}$ vs. RHE at the scan rates of 5, 10, 20, 40,80 and $160 \mathrm{mV} \cdot \mathrm{s}^{-1}$ in $1.0 \mathrm{M} \mathrm{KOH}$ solution. 


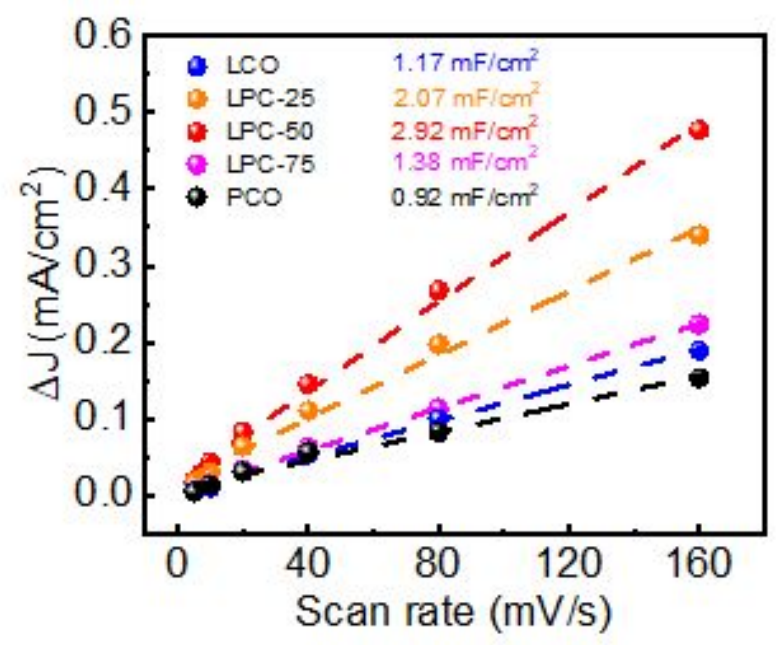

Figure S7 Plots of average double layer capacitive currents as a function of the scan rate for catalysts. The double-layer capacitance values were obtained by performing the linear fitting.

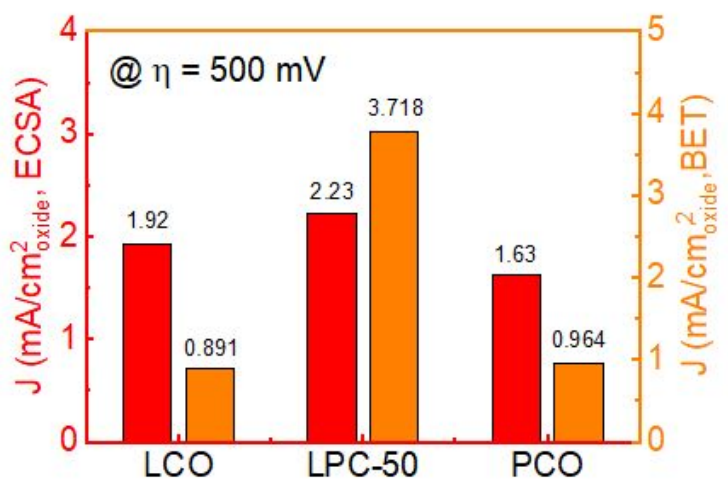

Figure S8 The specific activity of LCO, LPC-50 and PCO normalized respect to the surface areas obtained from ECSA and BET at $500 \mathrm{mV}$ overpotential

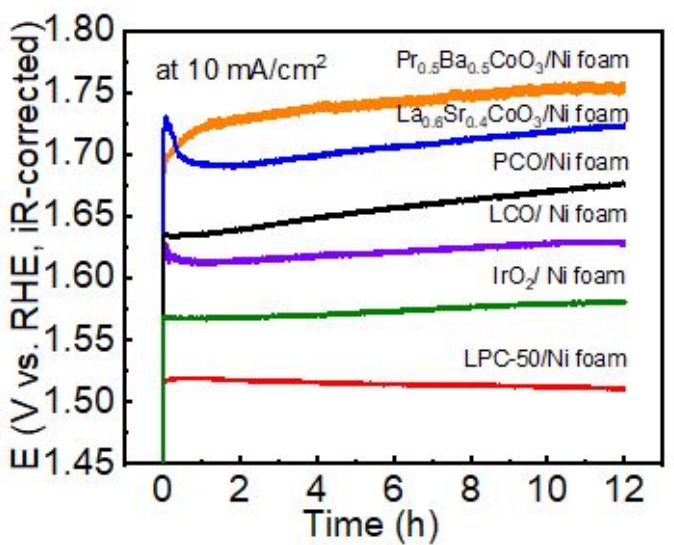

Figure S9 Chronopotentiometric measurements of LCO, LPC-50, PCO, $\operatorname{IrO}_{2}, \mathrm{Pr}_{0.5} \mathrm{Ba}_{0.5} \mathrm{CoO}_{3}$ and 
$\mathrm{La}_{0.6} \mathrm{Sr}_{0.4} \mathrm{CoO}_{3}$ supported on $\mathrm{Ni}$ foam at $10 \mathrm{~mA} \cdot \mathrm{cm}^{-2}$.

The XPS peaks of O 1s and Co 2p of the as-prepared and post-OER LPC-50 catalyst are recorded in Fig. S10. New features can be clearly seen for O 1s after OER test. The peaks located at 529.1 and $533.5 \mathrm{eV}$ are lattice oxygen $\left(\mathrm{O}_{\mathrm{L}}\right)$ and surface oxygen $\left(\mathrm{O}_{\mathrm{S}}\right)$, respectively. The relative intensity of $\mathrm{O}_{\mathrm{S}}$ peak was higher than $\mathrm{O}_{\mathrm{L}}$ peak after OER, which indicates that more surface adsorbed oxygen species in post-OER LPC-50 catalyst. And, the new peak at around $533.5 \mathrm{eV}$ was observed and was related to the adsorbed water ${ }^{10}$. However, Co $2 \mathrm{p}$ spectra showed no obvious change between asprepared and post-OER LPC-50 catalyst. In addition, the area ratio of $\mathrm{Co} /(\mathrm{La}+\mathrm{Pr}+\mathrm{Co})$ are 0.3427 for as-prepared catalyst and 0.3428 for post-OER catalyst. Therefore, it is reasonable to conclude that LPC-50 shows high stability during OER reaction.
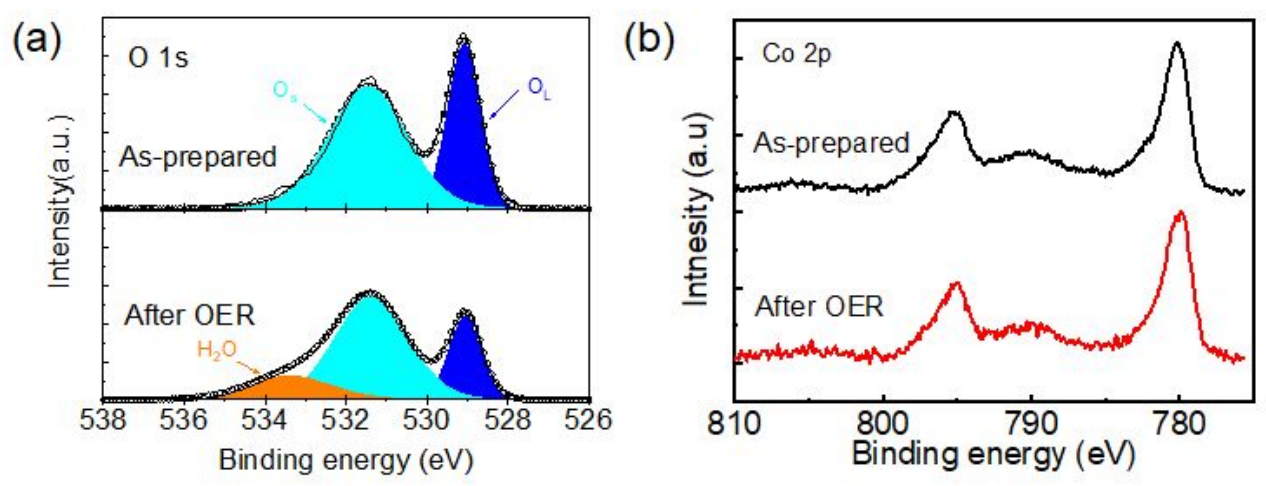

Figure S10 The XPS spectra of (a) O 1s and (b) Co 2p of as-prepared and post-OER LPC-50 catalyst 
(a)

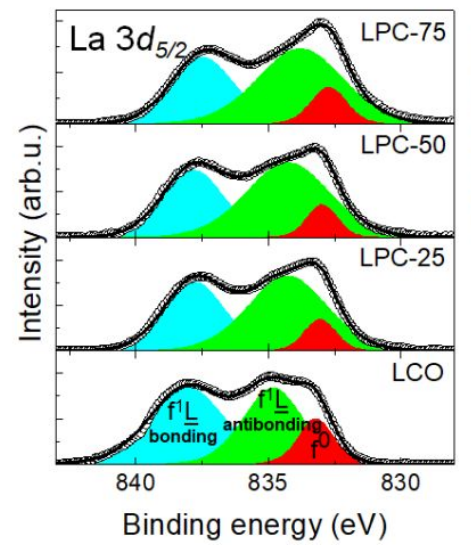

(b)

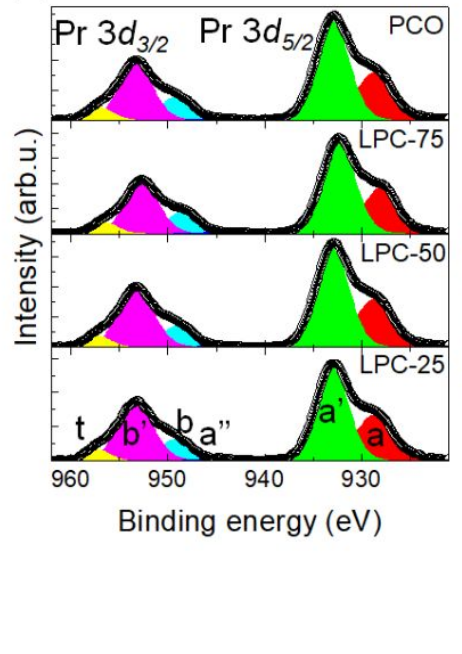

(c)

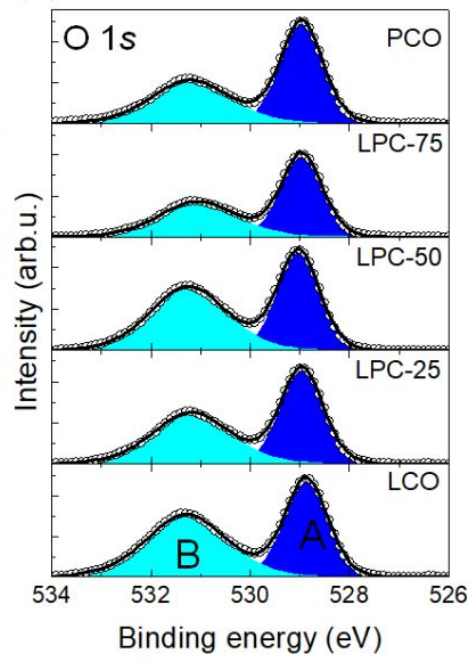

Figure S11 (a) La $3 d$, (b) Pr $3 d$ and O $1 s$ core level XPS spectra of LCO, LPC-25, LPC-50, LPC75 , and PCO powders.

The position of BE was calibrated with respect to $\mathrm{C} 1 \mathrm{~s}$ spectra $(284.8 \mathrm{eV})$. La $3 d$ core level spectra in Fig. S11a are typical of $\mathrm{La}^{3+}$ valence state. They show the two $3 d_{3 / 2}$ and $3 d_{5 / 2}$ spin-orbit split main components, each of them is very complex. It has been reported that two satellites corresponding to the charge transfer from the valence band of the ligand atom ( $\mathrm{f}^{1} \underline{\mathrm{L}}$ antibonding and bonding , at lower and higher BE respectively) must be added to the main component corresponding to the final state without charge transfer $\left(\mathrm{f}^{0}\right)^{11-13}$. The bonding charge transfer component is 3.9-4.9 eV higher than the main peak and the antibonding charge transfer component is $3.7-2 \mathrm{eV}$ higher than the antibonding one. However, the presence surface contaminants can give rise to further contributions from surface lanthanum species having lower BEs partially superimposed to the charge transfer satellites ${ }^{14-15}$. To keep the number of fitting components to a minimum we used only 3 components bearing in mind that they are the average of different lanthanum contributions in the film. The main results of the fitting procedure obtained after subtraction of the Shirley background are reported in Table S3.

Table S3 Binding energy (BE), FWHM and area percent of the La $3 d_{5 / 2}$ fitting components of LCO, LPC-25, LPC-50, LPC-75, and PCO. 


\begin{tabular}{llllll}
\hline Sample & & LCO & LPC-25 & LPC-50 & LPC-75 \\
\hline $\mathbf{f}^{\mathbf{0}}$ & BE (eV) & 833.20 & 833.05 & 832.97 & 832.72 \\
& FWHM & 1.56 & 1.39 & 1.36 & 1.59 \\
& Area (\%) & 14.06 & 8.62 & 8.33 & 10.71 \\
$\mathbf{f}^{\mathbf{1}} \underline{\mathbf{L}}$ & BE (eV) & 834.82 & 834.28 & 834.27 & 833.80 \\
antibonding & FWHM & 2.66 & 3.48 & 3.70 & 3.80 \\
& Area (\%) & 37.50 & 53.45 & 55.00 & 53.57 \\
$\mathbf{f}^{\mathbf{1}} \underline{\mathbf{L}}$ & BE (eV) & 838.06 & 837.80 & 837.84 & 837.47 \\
bonding & FWHM & 3.33 & 2.73 & 2.76 & 2.80 \\
& Area (\%) & 48.44 & 37.93 & 36.67 & 35.71 \\
\hline
\end{tabular}

$\operatorname{Pr} 3 d$ core level spectra are reported in Fig. S11b. They are splitted in $3 d_{3 / 2}$ and $3 d_{5 / 2}$ spin-orbit doublets each of them composed by three components: a, a', a' and b, b', b', the last one not included in our BE measurement range. Multiplet effects give rise to an additional component observed in $3 d_{3 / 2}$ core level and labeled as $\mathrm{t}^{16-18}$.

The main results of the fitting procedure obtained after subtraction of the Shirley background are reported in Table S4. As reported in $\operatorname{ref}^{16}, \mathrm{Pr}^{3+}$ concentration can be obtained by the formula:

$$
\frac{\left[\operatorname{Pr}^{3+}\right]}{\left[\operatorname{Pr}^{3+}+\operatorname{Pr}^{4+}\right]}=1-\frac{1}{0.28} \cdot \frac{\operatorname{Area}\left(a^{\prime \prime}\right)}{\operatorname{Area}\left(a^{\prime}\right)}
$$

We obtain that $\operatorname{Pr}^{3+}$ concentration ranges from about $80 \%$ in PCO to $95 \%$ in LPC-25.

Table S4 Binding energy (BE), FWHM and area percent of the Pr $3 d$ fitting components of LPC25, LPC-50, LPC-75 and PCO.

\begin{tabular}{llllll}
\hline Sample & & LPC-25 & LPC-50 & LPC-75 & PCO \\
\hline a & BE (eV) & 928.63 & 928.65 & 928.00 & 928.62 \\
& FWHM & 4.63 & 4.57 & 4.19 & 4.54 \\
a' & Area (\%) & 22.80 & 22.47 & 21.48 & 22.06 \\
& BE (eV) & 933.02 & 933.00 & 932.38 & 932.99 \\
& FWHM & 3.92 & 4.00 & 4.05 & 4.04 \\
a, & Area (\%) & 38.93 & 40.39 & 41.58 & 40.74 \\
& BE (eV) & 946.13 & 946.00 & 945.49 & 946.12 \\
& FWHM & 4.00 & 4.00 & 4.00 & 4.00 \\
b & Area (\%) & 0.64 & 0.37 & 0.61 & 0.48 \\
& BE (eV) & 949.29 & 949.00 & 948.52 & 949.18 \\
& FWHM & 3.72 & 3.73 & 3.78 & 3.95 \\
b & Area (\%) & 8.34 & 8.19 & 9.22 & 9.19 \\
& BE (eV) & 953.3 & 953.25 & 952.67 & 953.27 \\
\hline
\end{tabular}




\begin{tabular}{llllll}
\hline & Area (\%) & 26.03 & 25.29 & 23.44 & 23.57 \\
$\mathbf{t}$ & BE (eV) & 957.18 & 957.13 & 956.45 & 956.96 \\
& FWHM & 2.80 & 2.96 & 2.97 & 3.16 \\
& Area (\%) & 3.26 & 3.29 & 3.67 & 3.94 \\
\hline
\end{tabular}

The O $1 s$ core level spectra shown in Fig. S11c shows at least two main components. The lower binding energy component at about $529 \mathrm{eV}$ (named $\mathrm{A}$ in the figure) corresponds to the perovskite lattice oxygen $\mathrm{O}^{2-}$, which in our case can be oxygen bonded to $\mathrm{La}$, Pr, i.e. the $\mathrm{A}$ site cations or to $\mathrm{Co}$, i.e. the $\mathrm{B}$ site cations of $\mathrm{ABO}_{3}$ perovskite. Those two components are very close in BE, with an expected separation of the order of $1 \mathrm{eV}$. Furthermore, the component at about $531.5 \mathrm{eV}$ (named B in the figure) corresponds to O-containing surface species such as carbonate and/or hydroxyl groups ${ }^{14}$. The main results of the fitting procedure obtained after subtraction of the Shirley background are reported in Table S5.

Table S5 Binding energy (BE), FWHM and area percent of O $1 s$ fitting components of LCO, LPC25, LPC-50, LPC-75 and PCO.

\begin{tabular}{lllllll}
\hline \multicolumn{2}{l}{ Sample } & LCO & LPC-25 & LPC-50 & LPC-75 & PCO \\
\hline A & BE (eV) & 528.86 & 528.95 & 529.02 & 528.96 & 528.96 \\
& FWHM & 1.01 & 0.99 & 0.98 & 0.97 & 0.99 \\
& Area (\%) & 45.60 & 50.39 & 46.02 & 55.63 & 55.83 \\
B & E (eV) & 531.28 & 531.18 & 531.23 & 531.06 & 531.20 \\
& FWHM & 1.89 & 1.83 & 1.80 & 1.80 & 1.85 \\
& Area (\%) & 54.40 & 49.61 & 53.98 & 44.37 & 44.17 \\
\hline
\end{tabular}

The Co $2 p$ XPS spectra of LCO, LPC-25, LPC-50, LPC-75, and PCO are shown in Fig. S12 after the Shirley background subtraction. The $2 p_{1 / 2}$ and $2 p_{3 / 2}$ spin-orbit doublet and the satellite shake-up peaks located at the higher BE with respect to the main peaks can be observed. The Co $2 p$ was fitted using the peak components A and B together with the satellite shake-up peaks $\mathrm{C}$ and $\mathrm{D}$ as shown in the figure ${ }^{19}$. The fitting results for $2 p_{3 / 2}$ can be found in Table S6. However, the presence of the different Co valence states can introduce more components in the fitting procedure. It is also reported that the satellite $\mathrm{C}$ at about $6 \mathrm{eV}$ higher than the $\mathrm{BE}$ of the main peak corresponds to $\mathrm{Co}^{2+}$ and the satellite $\mathrm{D}$ at about $10 \mathrm{eV}$ higher than the $\mathrm{BE}$ of the main peak corresponds to $\mathrm{Co}^{3+20}$. However, the main peak shape and distance in BE change a little with different Pr 
doping, demonstrating a very small stoichiometry deviation. In particular, the $\mathrm{BE}$ distance between $2 p_{3 / 2}$ and $2 p_{1 / 2}$ peaks ranges from $15.2 \mathrm{eV}$ to $15.3 \mathrm{eV}$ with increasing Pr doping, which roughly correspond to $\mathrm{Co}^{3+}$ and $\mathrm{Co}^{2.67+}$ valence state, respectively ${ }^{19}$. In addition, the satellite peak $\mathrm{C}$ intensity has the maximum at $\mathrm{x}=0.5$ (see Fig. S12b) which is in agreement with an enhanced charge transfer between the $\mathrm{O} 2 p$ and $\mathrm{Co} 3 d$ favored in case of IS state. We can also observe that the satellite peak D intensity increases with Pr content. Since the relative area for $\mathrm{Co}^{3+}$ and $\mathrm{Co}^{2+}$ satellites should be about $9 \%$ and $33 \%$ respectively, the $\mathrm{Co}^{2+}$ content is estimated about $22 \%$ at most in case of $\mathrm{PCO}^{20}$.
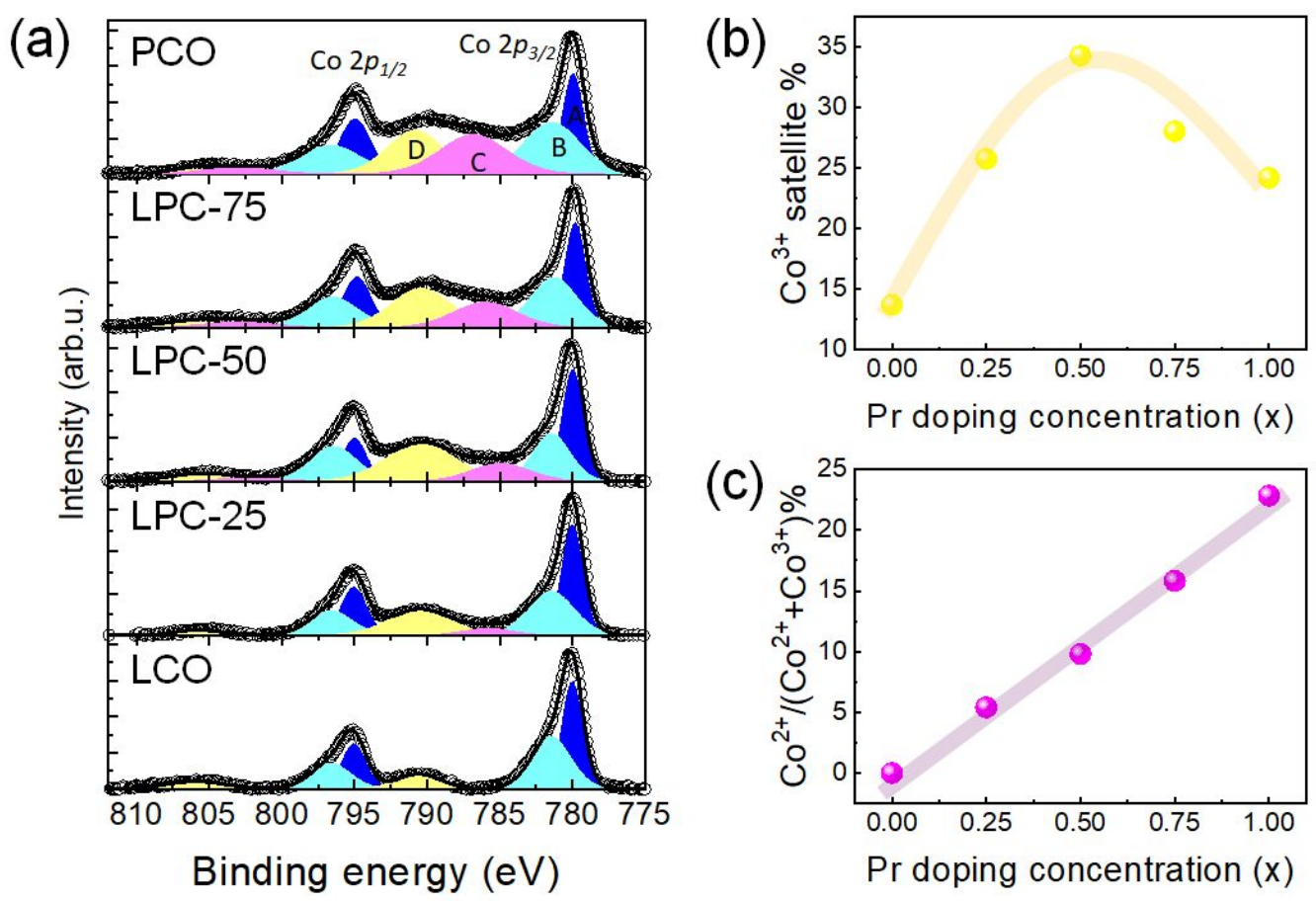

Figure S12 (a) Co $2 p$ XPS spectra of LCO, LPC-25, LPC-50, LPC-75 and PCO. (b) Concentration of satellite peak $\mathrm{C}$ with respect to the $\mathrm{Co} 2 \mathrm{p}_{3 / 2}$ total area which corresponds to the $\mathrm{Co}^{3+}$ charge transfer as described in the text. (c) Relative concentration of $\mathrm{Co}^{2+}$ valence state calculated from the $\mathrm{C}$ and D satellite peak area.

Table S6 Fitting results for the Co $2 \mathrm{p}_{3 / 2}$ : binding energy (BE), FWHM and area percent of the components with respect to the Co $2 \mathrm{p}_{3 / 2}$ total area in the LCO, LPC-25, LPC-50, LPC-75 and PCO. 


\begin{tabular}{lllllll}
\hline Sample & LCO & LPC-25 & LPC-50 & LPC-75 & PCO \\
\hline A & BE (eV) & 780.01 & 780.01 & 779.97 & 779.80 & 779.95 \\
& FWHM & 1.64 & 1.68 & 1.68 & 1.67 & 1.68 \\
& Area (\%) & 44.11 & 36.31 & 29.38 & 25.10 & 20.46 \\
B & BE (eV) & 781.46 & 781.46 & 781.43 & 781.26 & 781.41 \\
& FWHM & 3.20 & 3.75 & 3.04 & 3.81 & 4.64 \\
& Area (\%) & 42.16 & 32.53 & 22.69 & 27.52 & 29.06 \\
C & BE (eV) & & 785.80 & 784.95 & 786.00 & 786.82 \\
& FWHM & & 3.95 & 4.86 & 5.26 & 5.5 \\
& Area (\%) & & 5.40 & 13.66 & 19.33 & 26.28 \\
D & BE (eV) & 790.60 & 790.52 & 790.44 & 790.41 & 790.85 \\
& FWHM & 3.60 & 5.00 & 5.70 & 4.95 & 4.55 \\
& Area (\%) & 13.73 & 25.76 & 34.27 & 28.05 & 24.20 \\
\hline
\end{tabular}

From all the above consideration, the exact stoichiometry determination from the XPS measurements is highly questionable. However, from several survey scans and using the relative sensitivity factors 47.62 for $\operatorname{La} 3 d, 55.56$ for $\operatorname{Pr} 3 d, 19.2$ for Co $2 p, 2.93$ for $\mathrm{O} 1 s$, we obtain the behavior of the $\mathrm{O} /(\mathrm{La}+\mathrm{Pr}+\mathrm{Co}+\mathrm{O})$ and $\mathrm{Pr} /(\mathrm{La}+\mathrm{Pr}+\mathrm{Co}+\mathrm{O})$ area ratio reported in Fig. S13 compared with the expected stoichiometry of the samples. The O concentration slightly deviates from the expected values.
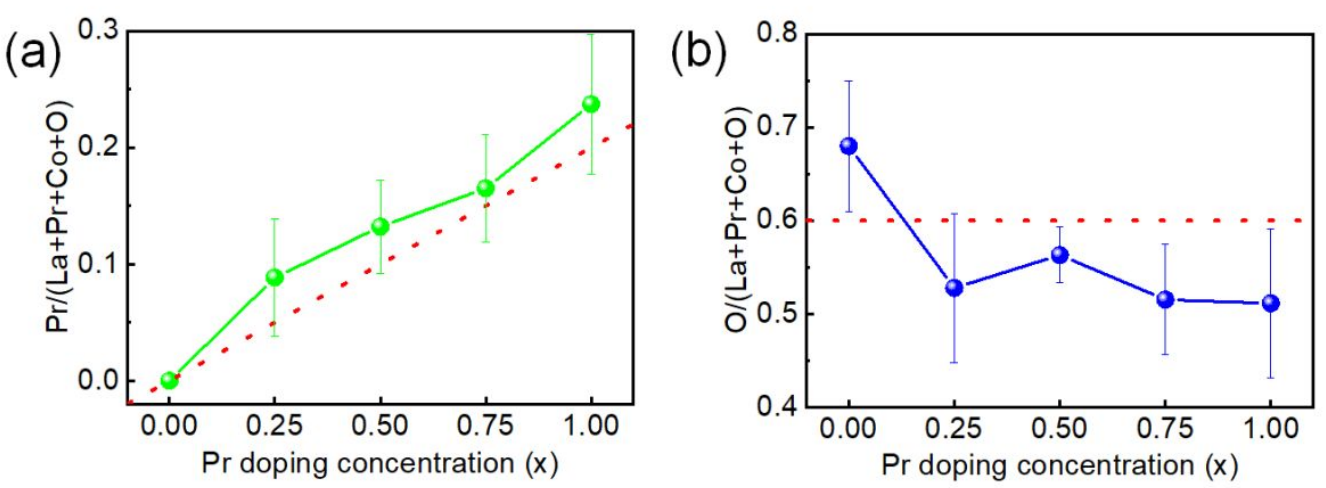

Figure S13 Chemical composition of $\mathrm{Pr}$ and $\mathrm{O}$. The stoichiometry expressed in terms of $\mathrm{Pr} /(\mathrm{La}+\mathrm{Pr}+\mathrm{Co}+\mathrm{O})$ in (a) and $\mathrm{O} /(\mathrm{La}+\mathrm{Pr}+\mathrm{Co}+\mathrm{O})$ in (b) area ratio. The doted red lines are the nominal values.

Qualitative fits of the valence band (VB) spectra were performed for all the samples and reported in Fig. S14 after subtracted the Shirley background. The fit components shown in the panel of PCO are labelled as A (mainly Co $3 d$ contribution), B (mainly O 
$2 p$ contribution), $\mathrm{C}$ and $\mathrm{D}$ (both containing Co $3 d$ contribution even with a less extent) ${ }^{21-}$ 22. Due to $\operatorname{Pr} 4 f$ contribution, we added an additional component in PCO and Pr-doped samples between the main $\mathrm{O} 2 p$ band (B component) and the Co $3 d$ band (A component) ${ }^{23}$. In addition, except for PCO, the component A must to be splitted into two contributions to obtain a reasonable fit. Such bands can be tentatively associated to $e_{\mathrm{g}}$ and $t_{2 \mathrm{~g}}$ bands. After fitted VB of $\mathrm{PCO}$ we fixed BE of $\operatorname{Pr} 4 f$ contribution of all the samples. The results of the fit procedure are reported in Table S7.

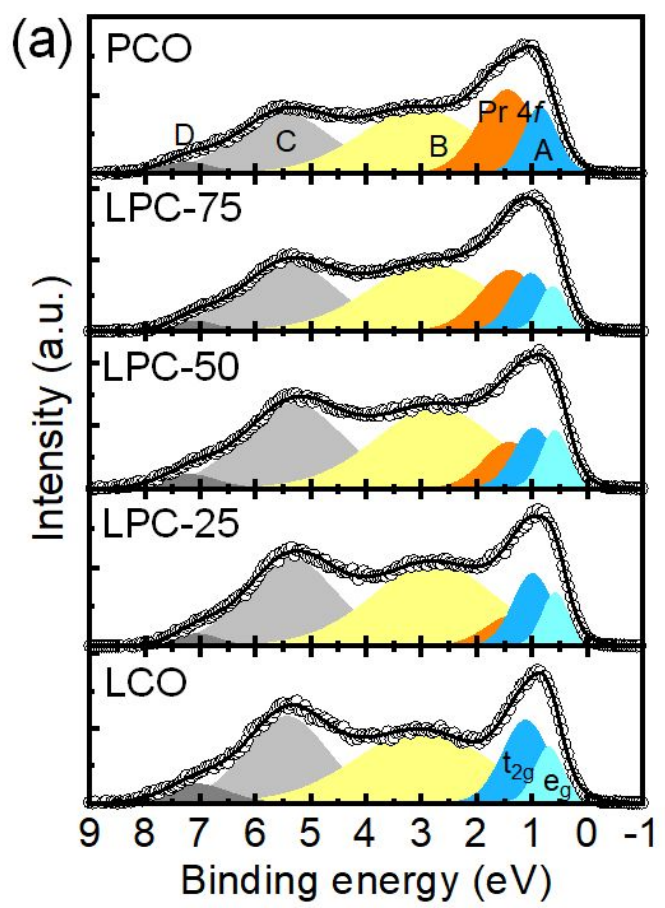

(b)

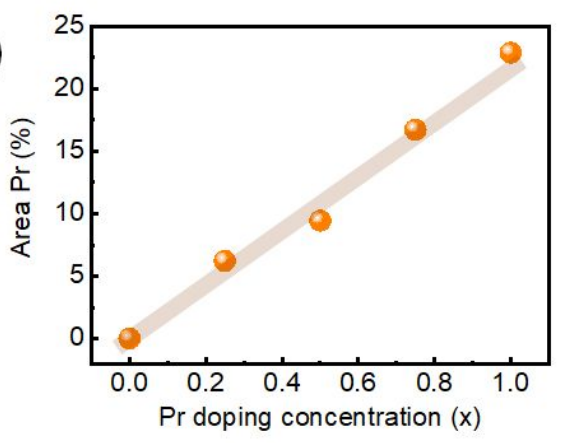

(C)

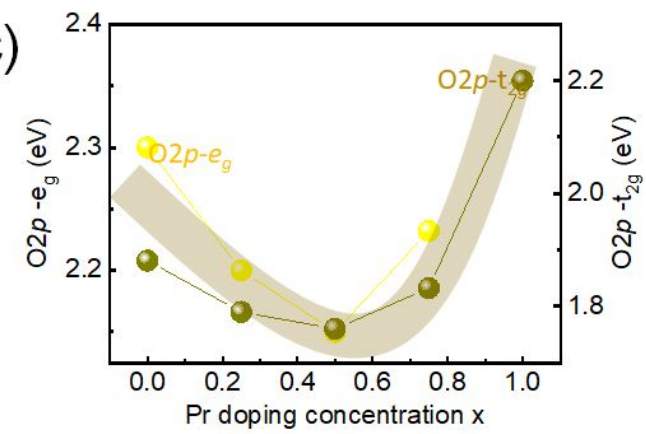

Figure S14 Valence band spectra and component analysis. (a) Valence band (VB) spectra of LCO, LPC-25, LPC-50, LPC-75 and PCO together with the fit as described in the text. (b) Behavior of the Pr component area\% with different Pr doping concentration x, obtained from the fit of panel (a). (c) $\mathrm{BE}$ difference between $\mathrm{O} 2 p$ band center and the two fitting components for Co $3 d$ associated to $\mathrm{t}_{2 \mathrm{~g}}$ (right axis) and $\mathrm{e}_{\mathrm{g}}$ (left axis).

Table S7 Binding energy (BE), FWHM and area percent of the VB fitting components of LCO, LPC-25, LPC-50, LPC-75 and PCO.

\begin{tabular}{llcllll}
\hline Sample & LCO & LPC-25 & LPC-50 & LPC-75 & PCO \\
\hline $\mathbf{e}_{\mathrm{g}}$ & $\mathbf{B E}(\mathbf{e V})$ & 0.69 & 0.58 & 0.58 & 0.62 & -- \\
& FWHM & 0.60 & 0.57 & 0.61 & 0.52 & -- \\
& Area (\%) & 6.83 & 5.75 & 6.39 & 4.78 & 0 \\
$\mathbf{t}_{2 \mathbf{g}}$ & $\mathbf{E}(\mathbf{e V})$ & 1.11 & 0.99 & 0.97 & 1.02 & 0.85 \\
\hline
\end{tabular}




\begin{tabular}{|c|c|c|c|c|c|c|}
\hline & FWHM & 0.99 & 0.83 & 0.86 & 0.83 & 0.72 \\
\hline & Area (\%) & 16.41 & 11.50 & 9.39 & 10.13 & 10.68 \\
\hline \multicolumn{2}{|c|}{$\operatorname{Pr} 4 f E(\mathrm{eV})$} & 0.15 & 1.39 & 1.41 & 1.40 & 1.45 \\
\hline & FWHM & -- & 1.10 & 1.12 & 1.30 & 1.24 \\
\hline & Area (\%) & 0 & 6.22 & 9.45 & 16.72 & 22.89 \\
\hline \multicolumn{2}{|c|}{ O2p E (eV) } & 2.99 & 2.78 & 2.73 & 2.85 & 3.05 \\
\hline & FWHM & 2.80 & 2.61 & 2.60 & 2.61 & 2.49 \\
\hline & Area (\%) & 40.97 & 41.44 & 38.33 & 37.07 & 35.85 \\
\hline \multirow[t]{3}{*}{$\mathrm{C}$} & $E(e V)$ & 5.43 & 5.36 & 5.3 & 5.45 & 5.48 \\
\hline & FWHM & 1.76 & 1.97 & 2.16 & 1.88 & 2.01 \\
\hline & Area (\%) & 30.50 & 32.85 & 33.39 & 29.33 & 27.68 \\
\hline \multirow[t]{3}{*}{ D } & $\mathrm{E}(\mathrm{eV})$ & 7.08 & 7.07 & 7.20 & 7.04 & 7.21 \\
\hline & FWHM & 1.37 & 0.96 & 1.18 & 1.06 & 1.17 \\
\hline & Area (\%) & 5.29 & 2.23 & 3.06 & 1.97 & 2.90 \\
\hline
\end{tabular}

\section{References:}

(1) Dai, J.; Zhu, Y.; Zhong, Y.; Miao, J.; Lin, B.; Zhou, W.; Shao, Z. Enabling High and Stable Electrocatalytic Activity of Iron-Based Perovskite Oxides for Water Splitting by Combined Bulk Doping and Morphology Designing. Adv. Mater. Interfaces 2018, 6 (1), DOI: 10.1002/admi.201801317.

(2) Majee, R.; Chakraborty, S.; Salunke, H. G.; Bhattacharyya, S. Maneuvering the Physical Properties and Spin States To Enhance the Activity of $\mathrm{La}-\mathrm{Sr}-\mathrm{Co}-\mathrm{Fe}-\mathrm{O}$ Perovskite Oxide Nanoparticles in Electrochemical Water Oxidation. ACS Appl. Energ. Mater. 2018, 1 (7), 3342-3350, DOI: 10.1021/acsaem.8b00531.

(3) Wan, M.; Zhu, H.; Zhang, S.; Jin, H.; Wen, Y.; Wang, L.; Zhang, M.; Du, M. Building Block Nanoparticles Engineering Induces Multi-Element Perovskite Hollow Nanofibers Structure Evolution to Trigger Enhanced Oxygen Evolution. Electrochim. Acta 2018, 279, 301-310, DOI: 10.1016/j.electacta.2018.05.077.

(4) Chen, G.; Hu, Z.; Zhu, Y.; Chen, Z. G.; Zhong, Y.; Lin, H. J.; Chen, C. T.; Tjeng, L. H.; Zhou, W.; Shao, Z. Ultrahigh-Performance Tungsten-Doped Perovskites for the Oxygen Evolution Reaction. $J$. Mater. Chem. A 2018, 6 (21), 9854-9859, DOI: 10.1039/c8ta02864h.

(5) Wang, C. C.; Cheng, Y.; Ianni, E.; Jiang, S. P.; Lin, B. A highly Active and Stable $\mathrm{La}_{0.5} \mathrm{Sr}_{0.5} \mathrm{Ni}_{0.4} \mathrm{Fe}_{0.6} \mathrm{O}_{3-\delta}$ Perovskite Electrocatalyst for Oxygen Evolution Reaction in Alkaline Media. Electrochim. Acta 2017, 246, 997-1003, DOI: 10.1016/j.electacta.2017.06.161.

(6) Du, B.; Meng, Q. T.; Sha, J. Q.; Li, J. S. Facile Synthesis of FeCo Alloys Encapsulated in NitrogenDoped Graphite/Carbon Nanotube Hybrids: Efficient Bi-Functional Electrocatalysts for Oxygen and Hydrogen Evolution Reactions. New J. Chem. 2018, 42 (5), 3409-3414, DOI: 10.1039/c7nj04555g.

(7) Zhu, Y. P.; Ma, T. Y.; Jaroniec, M.; Qiao, S. Z. Self-Templating Synthesis of Hollow $\mathrm{Co}_{3} \mathrm{O}_{4}$ Microtube Arrays for Highly Efficient Water Electrolysis. Angew Chem. Int. Ed. Engl. 2017, 56 (5), 1324-1328, DOI: 10.1002/anie.201610413.

(8) Lu, Y.; Ma, A.; Yu, Y.; Tan, R.; Liu, C.; Zhang, P.; Liu, D.; Gui, J. Engineering Oxygen Vacancies into $\mathrm{LaCoO}_{3}$ Perovskite for Efficient Electrocatalytic Oxygen Evolution. ACS Sustain. Chem. Eng. 2018, 7 (3), 2906-2910, DOI: 10.1021/acssuschemeng.8b05717.

(9) Fujiwara, N.; Nagai, T.; Ioroi, T.; Arai, H.; Ogumi, Z. Bifunctional Electrocatalysts of Lanthanum- 
Based Perovskite Oxide with Sb-Doped $\mathrm{SnO}_{2}$ for Oxygen Reduction and Evolution Reactions. J. Power Sources 2020, 451, DOI: 10.1016/j.jpowsour.2020.227736.

(10) Oh, N. K.; Kim, C.; Lee, J.; Kwon, O.; Choi, Y.; Jung, G. Y.; Lim, H. Y.; Kwak, S. K.; Kim, G.; Park, H. In-Situ Local Phase-Transitioned $\mathrm{MoSe}_{2}$ in $\mathrm{La}_{0.5} \mathrm{Sr}_{0.5} \mathrm{CoO}_{3-\mathrm{d}}$ Heterostructure and Stable Overall Water Electrolysis Over 1000 Hours. Nat. Commun. 2019, 10 (1), 1723, DOI: 10.1038/s41467-01909339-y.

(11) Sunding, M. F.; Hadidi, K.; Diplas, S.; Løvvik, O. M.; Norby, T. E.; Gunnæs, A. E. XPS Characterisation of in Situ Treated Lanthanum Oxide and Hydroxide Using Tailored Charge Referencing and Peak Fitting Procedures. J. Electron Spectrosc. 2011, 184 (7), 399-409, DOI: 10.1016/j.elspec.2011.04.002.

(12) Estruch Bosch, C.; Copley, M. P.; Eralp, T.; Bilbé, E.; Thybaut, J. W.; Marin, G. B.; Collier, P. Tailoring the Physical and Catalytic Properties of Lanthanum Oxycarbonate Nanoparticles. Appl. Catal. A: General 2017, 536, 104-112, DOI: 10.1016/j.apcata.2017.01.019.

(13) Mullica, D. F.; Lok, C. K.; Perkins, H. O.; Young, V. V. X-ray Photoelectron Final-State Screening in $\mathrm{La}(\mathrm{OH})_{3}$ : A Multiplet Structural Analysis. Phys. Rev. B: Condens. Matter. 1985, 31 (6), 4039-4042, DOI: $10.1103 /$ physrevb.31.4039.

(14) Heide, V. D. P. A. W. Systematic X-Ray Photoelectron Spectroscopic Study of $\mathrm{La}_{1-\mathrm{x}} \mathrm{Sr}_{\mathrm{x}}$-Based Perovskite-Type oxides. Surf. Interface Anal. 2002, 33 (5), 414-425, DOI: 10.1002/sia.1227.

(15) Mutoro, E.; Crumlin, E. J.; Biegalski, M. D.; Christen, H. M.; Shao-Horn, Y. Enhanced Oxygen Reduction Activity on Surface-Decorated Perovskite Thin Films for Solid Oxide Fuel Cells. Energ. Environ. Sci. 2011, 4 (9), DOI: 10.1039/c1ee01245b.

(16) Holger Borchert, Y. V. F., Vasiliy V. Kaichev, Igor P. Prosvirin,Galina M. Alikina, Anton I. Lukashevich, Vladimir I. Zaikovskii, Ella M. Moroz, Sergei N. Trukhan, Vyacheslav P. Ivanov, Eugenii A. Paukshtis, Valerii I. Bukhtiyarov, and Vladislav A. Sadykov. Electronic and Chemical Properties of Nanostructured Cerium Dioxide Doped with Praseodymium. J. Phys. Chem. B 2005, 109, 5728-5738.

(17) Bianconi, A.; Kotani, A.; Okada, K.; Giorgi, R.; Gargano, A.; Marcelli, A.; Miyahara, T. ManyBody Effects in Praesodymium Core-Level Spectroscopies of $\mathrm{PrO}_{2}$. Phys. Rev. B: Condens. Matter. 1988, 38 (5), 3433-3437, DOI: 10.1103/physrevb.38.3433.

(18) Ogasawara, H.; Kotani, A.; Potze, R.; Sawatzky, G. A.; Thole, B. T. Praseodymium 3d- and 4dCore Photoemission Spectra of $\operatorname{Pr}_{2} \mathrm{O}_{3}$. Phys. Rev. B: Condens. Matter. 1991, 44 (11), 5465-5469, DOI: 10.1103/physrevb.44.5465.

(19) Zhu, Z.; Shi, Y.; Aruta, C.; Yang, N. Improving Electronic Conductivity and Oxygen Reduction Activity in Sr-Doped Lanthanum Cobaltite Thin Films: Cobalt Valence State and Electronic Band Structure Effects. ACS Appl. Energy Mater. 2018, DOI:10.1021/acsaem.8b00931.

(20) Dedryvère, R.; Laruelle, S.; Grugeon, S.; Poizot, P.; Gonbeau, D.; Tarascon, J. M. Contribution of X-ray Photoelectron Spectroscopy to the Study of the Electrochemical Reactivity of $\mathrm{CoO}$ toward Lithium. Chem. Mater. 2004, 16 (6), 1056-1061, DOI: 10.1021/cm0311269.

(21) Saitoh, T.; Mizokawa, T.; Fujimori, A.; Abbate, M.; Takeda, Y.; Takano, M. Electronic Structure and Magnetic States in $\mathrm{La}_{1-\mathrm{x}} \mathrm{Sr}_{\mathrm{x}} \mathrm{CoO}_{3}$ Studied by Photoemission and X-ray-Absorption Spectroscopy. Phys. Rev. B 1997, 56 (3), 1290. DOI: 10.1103/PhysRevB.55.4257

(22) Saitoh, T.; Mizokawa, T.; Fujimori, A.; Abbate, M.; Takeda, Y.; Takano, M. Electronic Structure and Temperature-Induced Paramagnetism in $\mathrm{LaCoO}_{3}$. Phys. Rev. B 1997, 55 (7), 4257. DOI: 10.1103/PhysRevB.56.1290

(23) Pandey, S. K.; Patil, S.; Medicherla, V. R. R.; Singh, R. S.; Maiti, K. Electronic Structure of $\mathrm{PrCoO}_{3}$ 
and its Temperature Evolution. Phys. Rev. B 2008, 77 (11), DOI: 10.1103/PhysRevB.77.11513 